\title{
Response of wildebeest (Connochaetes taurinus) movements to spatial variation in long term risk from a complete predator guild
}

\begin{abstract}
$\underline{\text { Abstract }}$
Many studies have shown that behavioral responses to the risk posed by predators can
\end{abstract} carry costs for prey by reducing fecundity or survival, with consequent effects on population dynamics. Responses to risk include increased vigilance and reduced foraging, movement to safe habitats, increases or decreases in group size, and changes in patterns of movement. While we know that prey can detect and respond to both long term (LT) and short term (ST) variation in risk, field studies have only recently begun to consider how these responses might differ. Here, we hypothesize that prey movement patterns should respond differently to cues of LT and ST variation in risk. Specifically, cues of elevated LT risk might lead to decreased movement to improve the assessment of ST risk, while elevated ST risk might favor increased movement to reduce the proximity or duration of risks that are already assessed to be acute. We further hypothesize that decreases in movement are likely to be a general response to LT risk, while responses to ST risk are likely to vary in a manner that depends on the type of predator. In Liuwa Plain National Park, we found that wildebeest movements responded to the local intensity of predator use (LT risk), after controlling for other seasonal, diurnal and bottom-up effects. Speed decreased considerably and turning angles increased considerably, combining to markedly decrease linear movements. In contrast, immediate encounters with predators (ST risk) typically provoked fast, linear flight, and this effect was stronger for encounters with coursing predators. The effect of long term risk was to cause wildebeest to move more slowly and less linearly, i.e. to slow down and turn around, as part of a suite of behavioral responses, which also includes increased vigilance, that promote cautious assessment of ST risks when in locations with high levels of 
LT risk. This result has broad implications of understanding the influence of predation risk on foraging patterns of ungulates as this relationship is much more complex than simple avoidance of areas of 'high risk'.

Keywords: Risk-effects, predator-prey interactions, landscape of fear, anti-predator responses, spatio-temporal scale

\section{$\underline{\text { Introduction }}$}

Many studies have shown that behavioral responses to the predation risk can carry costs for prey by reducing fecundity or survival, with effects on population dynamics (Werner et al. 1983; Peckarsky et al. 1993; Boonstra et al. 1998; Pangle et al. 2007; Sheriff et al. 2009; LaManna et al. 2016). In ungulates, as in most other taxa, responses to risk include increased vigilance and reduced foraging (Winnie et al. 2007; Périquet et al. 2012; Broekhuis et al. 2013), movement to safe habitats (Creel et al. 2005; Valeix et al. 2009), increases or decreases in group size (Elgar 1989; Fitzgibbon 1990; Creel \& Winnie 2005), and changes in patterns of movement (Basille et al. 2015). Risk varies at multiple spatial and temporal scales, and studies to date have documented responses to both short term (ST) and long term (LT) variation in risk, but few studies have measured risk at more than one scale or explicitly considered how the scale of risk should affect optimal responses. Ecological studies often test responses of prey to LT variation in risk by quantifying how some measure of risk varies across space (with data aggregated over time) (Hebblewhite et al. 2002; Kauffman et al. 2007). In contrast, behavioral studies often record responses of prey to ST variation in risk, where risk is measured as the distance to the present predator (and modifying factors such as predator species, group size, etc.). With this approach, data are usually aggregated over space, i.e., the attributes of a predator-prey encounter are considered, but not its geographic location (e.g., Creel et al. 2014). These alternative approaches have been termed the 'risky 
places' and the 'risky times' hypotheses respectively (Creel et al. 2008) and much has been learned from each. Considerable evidence now shows that prey can detect and respond to both risky places and risky times (Brown et al. 2014), but research has only begun to consider how antipredator behavior might differ in response to ST and LT risks (Droge et al. 2017). Here, we hypothesize that prey movement patterns, in particular, should respond differently to LT risk and ST risk. For example, in situations of elevated LT risk (e.g., cues or memories that predators often use an area), selection might favor slower movements that allow more careful assessment of ST risk during foraging movements. In response to elevated ST risk (e.g., direct encounter with a predator), selection might favor fast movements that reduce exposure to risks that are already assessed to be acute (at the extreme, full-speed flight once attacked). We further hypothesize that slower movement is likely to be a general response in response to LT risk, but that the optimal response to ST risk is likely to vary according to the behavioral specifics of predator-prey interaction. Stalking predators that rely on short, ambush hunts, like lions and cheetahs, are less successful if they are detected prior to attack (Fitzgibbon 1989), so increased vigilance may be more effective than altered movement in response to cues of the ST presence of a stalker. In contrast, coursing predators that rely on open pursuit, like hyenas and African wild dogs, remain dangerous once detected, so moving away while still at a relatively safe distance is likely to reduce ST risk from a detected courser.

To date, experimental studies of the effect of risk on movement patterns have primarily examined responses to simulations of ST risk, including caged predators (Skelly et al. 2016), predators rendered incapable of killing prey (Schmitz 2012), and olfactory cues of predation events (the combined scents of predators and crushed prey: Sih \& McCarthy 2002). These experiments have yielded variable results. For example, snails responded to predatory crayfish by retreating to safe locations and reducing movement (Sih \& McCarthy 2002), but 
mayflies responded to predatory caddisflies with rapid movement by drifting (Peckarsky et al. 1993). While these effects on the speed of movement are in opposite directions, the inference in both studies was that prey responded to immediate risk in a manner that reduced the likelihood of being attacked. McCarthy \& Fisher (2000) compared the responses of snail prey to cues of LT risk and ST risk from crayfish, and found that LT risk (non-foraging crayfish scent) provoked increased movement to the surface, while ST risk (injured prey scent) provoked decreased movement and burrowing in the substrate.

Studies of ungulates facing predation risk from large carnivores (the focus of this study) have also found variable effects of ST risk on movement. Basille et al. (2015) found that woodland caribou moved faster when they were within $2.5 \mathrm{~km}$ of wolves (a coursing predator), and Proffitt et al. (2009) found that elk moved more quickly when they were within $5 \mathrm{~km}$ of wolves in a very open study area. In contrast, Creel et al. (2005) found that elk in a mosaic of forest and meadows moved more slowly on days that wolves were within the same local drainage (with a mean radius of $4.9 \mathrm{~km}$ ), though this effect was much weaker than simultaneous changes in habitat selection. Latombe et al. (2014) used a step selection function incorporating step lengths and turning angles to examine the response of moose and caribou movements to wolves, and found similar results: the recent passage of wolves within $5 \mathrm{~km}$ had strong effects on habitat selection, but effects on the speed of movement varied between species and seasons in both strength and sign. Martin \& Owen-Smith (2016) found that zebra and wildebeest both increased their rate of movement in the 2 hours after a probable encounter with lions, and that zebra moved more quickly over the subsequent 24 hours. Courbin et al. (2015) found that zebras moved more than twice as rapidly in the 24 hours after a probable encounter with lions, sometimes due to immediate flight over several kilometers, and sometimes due to 'delayed flight'. In general, it seems clear that an increase 
in speed (due to flight) is common if prey is directly hunted, but the effect of elevated ST risk that does not involve a direct attack is not clear.

Very little is known about the response of ungulate movements to variation in LT

risk. Fortin et al. (2005) used a step selection function to show that habitat selection by elk was affected by LT risk (the local intensity of use by wolves), but did not directly discuss the effect of LT risk on speed or turning angles. Frair et al. (2005) found that elk were more likely to make rapid, large movements ('relocating') in habitat types that had been more heavily used by wolves during a study conducted 15 years earlier. The inferences about risk

114 from this study design are limited because habitat type has effects on movement that are

115 independent of its use by predators, but to our knowledge, this is the most direct test to date

116 for an effect of natural variation in LT risk on the speed or linearity of ungulate movements.

117 While our focus here is on the relationship between LT risk and movement patterns, variation in LT risk (or the 'landscape of fear': (Laundré et al. 2001)) is known to affect many other aspects of ungulate behavior, ecology, physiology and demography (Creel et al. 2007; Valeix et al. 2009; Thaker et al. 2011; Périquet et al. 2012; Kuijper et al. 2013).

In this study, we used data from a 4-year field study to test how spatial variation in LT risk influenced the movement patterns of GPS-collared adult female wildebeest (Connochaetes taurinus) in Liuwa Plain National Park (LPNP), Zambia. We also tested how wildebeest movements responded to acute, ST risk during direct encounters with predators. LPNP is well suited for such a study because our $1200 \mathrm{~km}^{2}$ study site is an unusually homogeneous, open, flat grassland with very little variation in vegetation structure or topography. The homogeneity of the area offers no structural refuges for prey, and forage for grazing wildebeest is relatively evenly distributed across the landscape. The predator guild consists of both cursorial (African wild dog Lycaon pictus, and spotted hyena Crocuta crocuta) and stalking (lion Panthera leo, and cheetah Acinonyx jubatus) predators, allowing a 
strong test for differences in response to LT and ST risk from predators that hunt in different ways. We tested for effects of risk on both the speed and linearity of movement, controlling for other factors likely to affect movement, including the time of day, day of year, local

134 forage quality and quantity, proximity to water, reproductive status and autocorrelation. In ecosystems which hold migratory wildebeest and where they form a considerable part of the ungulate biomass, as is the case in the Greater Liuwa ecosystem, the species has a strong influence on ecosystem functioning and on the composition, size and distribution of the large carnivore guild, thus this study could provide insight into the relationship between wildebeests and large carnivores and aid in the conservation and management of these ecosystems.

\section{$\underline{\text { Study Area and Populations }}$}

Our data were gathered in a $1200 \mathrm{~km}^{2}$ study area in the southern part of the $3660 \mathrm{~km}^{2}$

147 Liuwa Plain National Park (LPNP) in Zambia. The vegetation in the study area is dominated by homogeneous short and intermediate grasslands with occasional tree islands. The ungulate community is dominated by migratory wildebeest (Connochaetes taurinus) with local densities ranging from $6.2-60.8$ individuals $/ \mathrm{km}^{2}$ and smaller populations of migratory zebra $\left(1.8-8.1\right.$ individuals $\left./ \mathrm{km}^{2}\right)$ and non-migratory oribi $\left(1.1-14.5\right.$ individuals $\left./ \mathrm{km}^{2}\right)\left(\mathrm{M}^{\prime}\right.$ Soka et al. 2017). These densities were estimated by distance sampling (which allowed correction for each species’ probability of detection) on a systematic grid of transects spaced at $4 \mathrm{~km}$ intervals, surveyed several times in each year of the study (M'Soka et al. 2017).

155

\section{$\underline{\text { Wildebeest Movement Data from GPS Collars }}$}

From 2010-06-24 to 2014-10-29, GPS collars from three manufacturers (African Wildlife Tracking, Telemetry Solutions and Telonics) were fitted to 19 adult female 
wildebeest. Twelve of the collars reported location errors (seven did not). In preliminary inspection of the data, five collars had large mean location uncertainty $(1,113 \mathrm{~m}-1,250 \mathrm{~m})$ and all five of these collars also had obviously erroneous locations. (i.e. multiple locations $>1$ $\mathrm{km}$ apart at near identical times) so they were removed from the dataset. Seven collars had an average location uncertainty of $15.4 \mathrm{~m}$ or less, and none of these seven collars had any obviously erroneous locations. The remaining 7 collars did not provide data on location uncertainty, but none of these showed biologically implausible movements, and they were retained in the dataset. Thus the final dataset included the movements of 14 adult female wildebeests, described by 10096 locations at 4 hour intervals between October 26, 2010 and October 29, 2014. Collared wildebeest were directly observed about once a month, and more frequently at the time of calving. These observations were used to assess reproductive status and parturition date. At each sighting of a collared wildebeest cow a detailed record of herd composition was made, and special attention was paid to each collared wildebeest cow to determine if she had a calf. Especially during the first month after parturition, calves are typically found within meters of their mothers with an obvious association.

\section{Movement Rates and Turning Angles}

We calculated the speed of movement (in $\mathrm{km} / \mathrm{h}$ ) between consecutive locations by dividing the distance between consecutive points (a step: Turchin 1998) by the time difference between those points. For each step, we associated this speed with the location of the starting point of the step. As shown in Appendix I, we determined two measures of the change in direction between consecutive steps. The deflection angle $(\beta)$ for a location was the difference between the bearings of the steps approaching and leaving that point and was calculated using the ltrai function of the AdehabitatLT package (Calenge 2006). The 
187

188

189

190

191

192

193

194

195

196

197

198

199

200

201

202

203

204

205

206

207

208

209

210

211

212

leaving that point (from $t$ to $t+1$ ) and the bearing between $t$ and $t+2$. Deflection angle is not affected by step length, but displacement angle is. Changes in direction to the left or right were considered equivalent, so that all angles fell between 0 and 180 degrees.

The speed and linearity of animal movements determined from GPS collars often show strong temporal autocorrelation, so to avoid pseudo-replication our linear models of effects on speed and angles of movement included a first order autoregression term. In Appendix I, the deflection angle $\beta_{1}$ is the autoregressive predictor of $\beta_{2}$ and the speed in Step 1 is the autoregressive predictor of speed in Step 2.

\section{$\underline{\text { Predator Data and Populations }}$}

The study area was occupied by 4 hyena clans totaling about 150 animals (M’Soka et al. 2016a), 6 lions forming 1 cohesive pride, two wild dog packs with a total of 22 individuals and 17 known cheetahs. Leopards are not present in LPNP. Wildebeest constituted $\geq 90 \%$ of kills by hyenas and lions, 59\% of kills by wild dogs and 30\% of kills by cheetahs (for which oribi were the most common prey) (Dröge et al. 2017). A detailed description of predator location data used in this study can be found in (Droge et al. 2017) while a visual representation of resulting utilization distributions (see below) can be found in Dröge et al. (2017). In summary, we obtained representative data on the use of space within the 1,200 $\mathrm{km}^{2}$ intensive study area by each of the large carnivores, using a combination of GPS and VHF radiocollars. We obtained 1,713 locations for wild dogs, 4,725 locations for hyenas, 2,000 locations for cheetahs and 11,018 locations for lions. At least one member of each group of each species was radio-collared, except for one hyena clan that split off from a known clan during the study but remained within the same home range. All immobilization procedures to fit animals with collars were conducted with permission of the Department of National Parks and Wildlife (DNPW, formerly ZAWA), following animal welfare standards and protocols 
required by the Zambia Department of Veterinary and Livestock Services and the DNPW, and approved by MSU IACUC.

The location data for the four species come from overlapping periods from 2010 to 2015, but the interval sampled was not identical for all species. However, data from GPS

217 collars showed that the ranging patterns of lions and hyenas changed little year to year; there were frequent relocations for wild dogs during the period they used the site; and cheetah relocations showed no evidence of territorial partitioning of the study area among individuals. Together, these data suggest the sampled individuals provided representative data on space use by each species over the study period (Dröge et al. 2017).

222

Utilization Distributions Fit to Location Data to Quantify Long-term Spatial Variation in Risk

From the locations of the predators we calculated a utilization distribution (UD) for each species (Worton \& Worton 1989; Seaman et al. 1996) using the adehabitatHR package (Calenge 2006) in R (R Core Team 2016), with a grid cell size of 500 meters. This spatial scale was fine enough to provide a meaningful description of variation in space use, and the data for each species allowed us to fit UDs at this scale. To objectively select a reference bandwidth ( $\mathrm{h}_{\mathrm{ref}}$ ) we used the same method as we successfully used in Dröge et al. (2017), where we set $\mathrm{h}_{\text {ref }}$ equal to the $90^{\text {th }}$ percentile of the frequency distribution of daily distances moved to eliminate extreme movements $\left(95^{\text {th }}\right.$ for cheetahs, which had sparser data and few extreme movements) as the smoothing parameter. The smoothing parameter has a large influence on the shape and size of the UD with larger bandwidths smoothing more and leading to larger kernels with less change in utilization density between adjacent areas. Because the home ranges of the two wild dog packs and the four hyena clans had little overlap, UD’s were calculated separately for each group's homerange, then combined and rescaled to result in a total utilization of 1 for the combined UD of the species. This process 
properly resolved areas of low use between home ranges. For cheetahs and lions, individual ranges overlapped very substantially, so we calculated a single UD for each of these species.

It is possible that wildebeests respond primarily to predators on the basis of functional groups (e.g., stalkers vs. coursers) rather than species (Schmitz 2008; Thaker et al. 2011),

243 though tests of this hypothesis have shown variable results (e.g. Creel et al. 2014; Moll et al.

244 2016; Dröge et al. 2017). To test spatial responses of prey to functional groups of predators we combined the UD's of the coursing predators, hyenas and wild dogs, and those of stalking predators, cheetahs and lions, and again rescaled them to a total utilization of 1 . Finally, to calculate the utilization of the study area by all of the predators, we combined the UD's of all four species and again rescaled to a total utilization of 1 .

\section{Wildebeest Responses to Direct Encounters with Predators (ST Risk)}

Data on direct encounters between predators and prey were obtained during carnivore ‘follows’ which are extensively described elsewhere (Dröge et al. 2017). In short, radiocollared predators were followed for complete hunting periods (from when they became active until they became inactive), typically for several consecutive hunting periods. During these follows, we recorded the species (and when possible the age and sex) of prey that were encountered, hunted and killed. Here, we analyzed encounters of each predator species with wildebeests, to quantify the wildebeests' reaction (flight or no flight) and, if the encounter resulted in a chase, its distance. Confidence intervals for the proportion of encounters that provoked flight were calculated using the score method (Newcombe 1998). Chase distance was log transformed prior to analysis, and a Tukey pairwise comparison test was used to test

262 for differences between predator species, while a two-sample t-test was used to test for a

263 difference in mean chase distance between predator functional groups. 


\section{$\underline{\text { Covariates of Wildebeest Movement Patterns }}$}

As described below (see Model formation and data transformation), we used beta

268 regression models to test whether the speed or linearity of wildebeest movements was

269 correlated with LT risk (as described by carnivore utilization distributions) and AIC scores to 270 identify which models would best describe these relationships. Because ungulate movements

271 respond to variables other than risk, we included the following parameters (in addition to risk

272 and an autocorrelation term) in our models to control for their influence when testing for 273 responses to risk. 
274 Reproductive Status: A growing fetus or a calf at heel might restrict the distance a wildebeest

275

276

277

278

279

280

281

282

283

284

285

286

287

288

289

290

291

292

293

294

295

296

297

298

moved. We classified reproductive status in three categories: 'Not Affected', 'Pre Parturition' and 'Post Parturition'. For each female, the estimated date of parturition was determined as the midpoint between the last direct observation of the wildebeest without calf, and the first observation with a calf. We assigned "Pre Parturition" to the 30 days prior to parturition and 'Post Parturition' to the 30 days immediately after parturition, thus assuming that any effects on movement would be strongest at the end of gestation when the energetic cost of gestation is highest, or immediately after birth when calves are least capable (though quite precocial). The rest of the days of the year were assigned to 'Not Affected'. Distance to Water: As wildebeest need regular access to water, the distance from each wildebeest location to the nearest potential water source was calculated. The study area is flat with shallow depressions and is heavily inundated in the wet season, creating hundreds of pans (small ponds with no drainage). During field work we recorded the GPS coordinates of pans with water. These were cross-referenced with images from Google Earth, and unobserved pans were added by inspecting the study area with Google Earth at high resolution. Some pans retain water year round, so water in LPNP is never far in comparison to many ecosystems, but the distance to the nearest pan with water increases in the dry season as some pans dry out. Our analysis treats distance to water as a static variable (distance to the nearest location known to form a pan), because the data were not adequate to state which pans held water on a given date. Diet Quality: For grazing ungulates, dormant, senescent vegetation provides the least nutritional value while actively photosynthesizing tissue usually provides nutrients above maintenance levels (McNaughton 1979; Wilmshurst et al. 1995; Murray \& Illius 2000; Shrader et al. 2006). Annual photosynthetic cycles are conspicuous from leaf to landscape levels, and the influence of these cycles on diet quality can be measured by fecal chlorophyll concentration (Christianson \& Creel 2009, 2014). We determined seasonal variation in diet quality from the 
fecal chlorophyll concentration of 180 fecal samples collected throughout the year. Fresh fecal samples (30 ml each and up to 10 per herd) were collected from individual scats after observing a herd. These samples were frozen in liquid nitrogen until transportation to the laboratory. Methods of assay have been described previously (Christianson \& Creel 2009) but briefly, we extracted photosynthetic pigments by boiling a known mass of dry feces $(\sim 0.2$ g) in $10 \mathrm{ml}$ ethanol, drying under air in a water bath at $78.5 \mathrm{C}$ and reconstituting in $1 \mathrm{ml}$ methanol. Extracts were diluted 31-fold in methanol and scanned immediately on a 96-well microplate spectrophotometer. We determined optical density at $666 \mathrm{~nm}$ (peak absorption specific to chlorophylls, with correction for optical density at $750 \mathrm{~nm}$ to control for variation in turbidity) and expressed diet quality as optical density/0.2 g sample. To describe annual variation in diet quality in the strongly seasonal environment of LPNP, we identified the period for which fecal chlorophyll was above the median (Julian days 195-260) and below

311 the median and defined these periods as 'high' and 'low' diet quality, respectively.

312 Forage Quantity: The concentration of photosynthetic pigments has long been used to

313 quantify the 'greenness' of forage for herbivores and thus their quality (McNaughton 1979).

314 This approach has expanded to include landscape-scale indices of primary production derived

315 from satellite-imagery (Forchhammer \& Post 2004; Pettorelli et al. 2005; Christianson et al. 2013), which are affected by both the quality and quantity of green vegetation. As a measure

317 of local landscape-scale availability of green forage, we obtained Enhanced Vegetation Index

318 (EVI) values from the MODIS instrument on the Aqua and Terra satellites (Didan 2015). EVI

319 improves upon the Normalized Difference Vegetation Index (NDVI) by using spectral bands

320 that allow correction to remove soil-brightness induced variations, decoupling atmospheric influences from the vegetation signal and avoiding saturation of the signal at high productivity levels. Each of the two satellites records an image including the study site each day, but the MOD13DQ1 and MYD13Q1 data product provides the best image taken within a 
324 16-day window, with a pixel size of 250m. The 16-day image compositing period of the two satellites are offset by 8 days, providing a unique EVI measurement every 8 days on average, or within 4 days of each wildebeest location. In practice, with cloud- or smoke cover the average time-gap between the date of a wildebeest location, and an EVI value for the pixel including the wildebeest location was 4.8 days, with a standard deviation of 31.0 days and ranging from -112 days (before the wildebeest location was taken) to 124 days (after the wildebeest location was taken) indicating long periods with extensive cloud cover during the rainy season that prevented satellite measurement of EVI. was $<5$ days, we used a preliminary analysis to test if inferences were affected by the inclusion of points with longer time gaps. We fit a full model of the speed of movement (see Model formation and data transformation below) to all of the data, and then fit the same model to a data set restricted to locations with EVI values within 10 days. The estimated effect of EVI (and associated $P$ value) differed little between these models, and the estimated effect of risk on movements (the effect of primary interest) also changed little (see table in Appendix II). The only inference about movement that was altered by restriction of the data was that an effect of proximity to water was detected with the full data set but not with the restricted data. On the basis of this preliminary test, we present results using the full data set. 
342 Day of Year: As the wildebeest in the Greater Liuwa ecosystem, are migratory, the speed and

343 patterns of movement are expected to vary throughout the year. Because migration in this

344 system is partly driven by inundation of the low lying areas, seasonal changes in movement

345 may not be fully described by seasonal changes in forage quantity and quality. We accounted

346 for this effect by including distance to water, and to control any seasonal variation not

347 captured by reproductive status and these environmental variables, we also included the

348 Julian date of each location. We incorporated the Julian date in our model by fitting two

349 parameters that account for the cyclic nature of this variable. These parameters were $\sin (2 \pi *$

350 day of year / 365) and cosine $(2 \pi *$ day of year / 365).

351 Time of Day: As for most African ungulates, wildebeest activity in LPNP varies throughout

352 the day with obvious peaks around duskand dawn. We calculated the average speed of

353 movement per hour (Fig. 1, and categorized the 24-hour day into two classes, namely 'High

354 Activity Periods' (from 02:30 to 07:29 and 16:30 to 18:29) and 'Low Activity Periods'

355 (18:30 to 02:29 and 07:30 to 16:29).

356

357

358

359

360

361

362

363

364

365

366

367

368

369

\section{$\underline{\text { Statistical Models of Effects on Movement }}$}

For each dependent variable (speed and turning angle), we tested whether movement responded to LT risk using a linear model that accounted for autocorrelation between consecutive movements and controlled for other potential effects on movement (proximity to water, diet quality and forage quantity, day of year, time of day, and reproductive status). The details of model form differed for each dependent variable (see Model form just below).

\section{Model Form and Data Transformation}

Turning angles were constrained to a bounded interval between 0 and 180, so they were rescaled to the interval $[0,1]$ and modeled as beta distributed using the betareg package (Ferrari \& Cribari-Neto 2004, Cribari-Neto \& Zeileis 2010). 

common GLMs had clear problems with goodness of fit, so we applied a Box-Cox transformation to speed. With the MASS package (Venables \& Ripley 2002) in R (R Core Team 2016), the power-term for the Box-Cox transformation, $\lambda$, was determined to be 0.222 , and with this transformation, quartile-quartile and residual-predicted plots for an ordinary linear model showed no evidence of non-normality or heteroscedasticity. would suggest inclusion of a random effect of individual identity, but boxplots showed there was much more variation within wildebeest than between wildebeest (Fig. 2), so this term was not included. To compare magnitudes of coefficients from the models, we centered and scaled all continuous variables (subtracting the mean and dividing by the standard deviation, so that units for the coefficients are standard deviations).

For each dependent variable, our full model to assess which parameters were related to movements of wildebeests included the UD of all carnivores as a measure of LT risk, time of day, day of year as a linear combination of sine and cosine with equal periods, our measure of food quality from fecal chlorophyll, food quantity as estimated through EVI values, distance to water and reproduction status. We tested if the final models with a lag one autocorrelation term performed better than without and found that both in the speed model (AIC value 21,063 vs. 21,400$)$ and angle model $(-11,610$ vs. $-11,481)$ the model with the lag one autocorrelation term performed better.

\section{Alternative Measures of Long Term Risk}

To assess which measure of LT risk best explained effects on wildebeest movement we began with a full model in which LT risk was described by the UD for all predators, in addition to all other variables described above. We then used AIC scores to compare this model with otherwise identical models in which LT risk was expressed as the UD of each 
species of predator or by UD of each type of predator (coursers or stalkers). We also tested a model containing all variables but not LT risk. The set thus included eight models (risk from all predators, stalkers, coursers, lions, hyenas, cheetahs, wild dogs and no risk) and the best full model, based on AIC scores was selected. Subsequently we used likelihood ratio-test to test which individual parameters could be dropped from the full model. Several of the variables in the final model are seasonal and therefore potentially correlated. When a pair of predictors is correlated, one of them is often discarded because each affects the estimated coefficient for the other. Here, however, the primary purpose of including these variables is diligence in accounting for non-predator effects when testing for an effect of predation risk on movements, so we retained them. We checked if exclusion of correlated variables appreciably altered the magnitudes of estimated coefficients or test statistics for other effects, particularly predation risk. They did not, so we left all variables potentially influencing wildebeest movement in the model.

410

411

412

413

414

415

416

417

418

419

420

421

423 424

\section{$\underline{\text { Results }}$}

\section{$\underline{\text { Speed of Movement }}$}

Wildebeest moved more slowly in areas of high LT risk (Fig. 3), and the estimated effect of risk was larger than all other effects in the model other than diurnal variation, which (unlike the other predictors) was categorized directly on the basis of movements themselves (Fig. 1). With other effects held constant, the predicted speed of wildebeest in the areas of lowest risk was $0.14 \mathrm{~km} / \mathrm{h}$, while in areas of highest risk it was $0.06 \mathrm{~km} / \mathrm{h}$ : wildebeest moved 2.3 times more slowly in areas with high LT risk. After accounting for autocorrelation between consecutive steps, the speed of wildebeest movement was detectably affected by all covariates in the model except for reproductive status, diet quality and forage quantity (Table $1)$. 

found that the UD of all predators combined was best supported by the data, with $\triangle \mathrm{AIC}=$ 3.43 relative to the second-best model, which described risk as the UD of hyenas, the most abundant predator in this ecosystem (Table 2). The AIC score for coursers (hyenas and wild dogs) was third-best supported, with $\triangle \mathrm{AIC}=6.72$, and other alternatives had considerably weaker support. A model excluding LT risk had an AIC score 377 units worse than an otherwise identical model including LT risk (from all predators combined). Overall, these results strongly suggest that wildebeest are sensitive to an integrated measure of LT risk from all of the predators in this ecosystem. Given that wildebeest are the most common (for hyenas, lions, and wild dogs) or second most common (for cheetahs) prey for all of these carnivores in LPNP, this result is not surprising. Thus, for all further inferences (including analysis of turning angles), the model with LT risk described by the UD of all predators combined was used. As Figure 3 shows, the estimated effect of risk on speed of movement was similar for all measures of LT risk, and the inference that wildebeest move more cautiously in areas of high risk was supported by all measures of risk.

\section{Deflection and Displacement Angles}

The change in bearing between consecutive steps of wildebeest movement paths increased substantially in areas of high LT risk (Table 3, Fig. 4). As with speed of movement, displacement angles were affected by the time of day, day of year and forage quantity, but there was no evidence for a relationship to forage quality, distance to water and reproductive status (Table 3). associated with a substantial increase in deflection bearing changes $(b=0.185, \mathrm{SE}=0.041, \mathrm{z}$ $=4.46, P<0.0001)$. Back-transforming this effect to the original scale of 0 to 180 degrees, deflection angles in areas with the highest LT risk were $33.3^{\circ}$ larger than in areas with the 
lowest LT risk, and turns greater than $90^{\circ}$ were much more common (Fig. 4). Inferences

453

454

455

456

457

458

459

460

461

462

463

464

465

466

467

468

469

470

471

472

473

474

475

476

477

478

479 about the effect of risk (and other variables) on changes in bearing were not affected by the choice of deflection angle or displacement angle as the dependent variable.

\section{Combined Effects of Long Term Risk on Speed and Deflection}

Estimated average step length (over 4 hours) in areas with no risk was predicted to be 563 meters, while in areas with the highest LT risk step length was predicted to be 241 meters (holding all other effects constant). Estimated average deflection angles were predicted to be $88^{\circ}$ for areas with no LT risk and $121^{\circ}$ in areas with the highest LT risk (again holding other effects constant). We used the mean predicted speed and deflection to illustrate movement over 20 time steps with a random pattern of deflection to the left or right, and show two representative paths across grid cells of one $\mathrm{km}^{2}$ in Fig. 5 The combined effect of a reduction in speed and an increase in deflection is movement that allows much more prolonged assessment of each new cell that a wildebeest enters when in an area of high LT risk.

\section{$\underline{\text { Responses to Direct Encounters with Predators }}$}

Behavioral observations of wildebeest encountering predators during radio-collared carnivore follows showed that coursing predators were 7 times more likely to cause a flight response (Fig. 6) than stalking predators (proportion $=0.22$, 95\% CI 0.19-0.26, $N=487$ versus 0.03 , CI 0.02-0.06, $N=270$ respectively). These patterns were consistent for both coursers, with flight in response to $0.219(95 \%$ CI $0.18-0.27, \mathrm{~N}=343$ ) of encounters with African wild dog and 0.236 (95\% CI 0.17-0.32, $\mathrm{N}=144$ ) of encounters with hyenas, and for both stalkers, with flight in response to 0.0222 (95\% CI 0.0012-0.13, $\mathrm{N}=45$ ) of encounters with lions and 0.036 (95\% CI 0.017-0.072, $\mathrm{N}=225)$ of encounters with cheetahs (Fig. 6). Not surprisingly, the distance that wildebeest were pursued was greater for coursers than for stalkers $(t=3.37, d f=82, P=0.0012)$. Because relatively few chase distances could 
be recorded accurately, small sample sizes lead to wide confidence intervals for individual species, but the difference in response to stalkers and coursers was clear (Fig. 7 and Table 4).

\section{$\underline{\text { Discussion }}$}

The effect of immediate, short term exposure to predators is to increase the speed of movement. This increase in movement is relatively minor for responses to stalkers, because only a small fraction of these encounters provoke flight (wildebeest respond primarily with increased vigilance: Creel et al. 2017) with flight distance averaging only slightly over 100 meters. On the other hand, encounters with coursers more often provoke flight, and flight distances are considerably greater than the linear distance expected for a typical 4-hour step. Because encounters are more likely in areas of high use by carnivores, it is notable that wildebeests decreased their mean rate of movement in areas of high LT risk, even though one would expect that these wildebeest were more likely to engage in short term flight responses. That is, the reduction in speed in response to LT risk was apparent despite being offset by increased short-term movements in response to immediate risk, particularly from coursers. Overall there is considerable evidence that movements of wildebeests responded to the intensity of use of their location by predators, after controlling for diurnal and seasonally varying bottom-up effects on movement. Step lengths decreased and turning angles increased in response to LT risk. The only parameter with comparable estimated effects on movement is the time of day, a result that is expected because most African ungulates, including wildebeests, show strong diurnal differences in activity levels, and we categorized time periods directly on the basis of movement data (see Fig. 1). These results indicate that wildebeest are capable of assessing the LT risk associated with an area, perhaps by the immediate use of smell or perhaps by memory of past patterns of predator detection using sight, hearing and smell, all of which are acute for wildebeest. Because wildebeest are social, 
507 information might also be obtained from other wildebeest using sight, hearing or smell. Even 508 though immediate encounters with predators typically provoked fast, linear flight, the effect 509 of LT risk was to cause wildebeest to move more slowly and less linearly, i.e. to slow down 510 and turn more. The combined effect of slowing down and turning more is to allow wildebeest 511 more time to assess immediate ST risk when moving within an area of high LT risk (Fig. 7).

512 Even without improved assessment of ST risk, moving more slowly could reduce the 513 probability of encountering a predator (Gerritsen \& Strickler 1977) or being detected

514 (Cleveland et al. 2012; Little et al. 2016), particularly if animals confine themselves to 515 structural refuges. Because wildebeest in this study were moving almost entirely in open

516 grassland, it is unlikely that moving less was associated with 'hiding', but reduced movement 517 would nonetheless be expected to reduce encounter rates with randomly located predators 518 (Viswanathan et al. 1999). There is a trade-off, however, because predators were not randomly located - by slowing down and turning more in areas of high LT risk, wildebeest spend more time in these dangerous areas (Fig. 7). This response should also make their

521 location more predictable on a time scale of several days, and this predictability could be 522 exploited by predators to increase encounter rates. These patterns suggest that in a homogeneous, open environment without refuges, behavior that promotes wildebeests' ability to assess and detect ST risk is an important aspect of response to cues of high LT risk. Other studies in this ecosystem (Creel et al. 2017; Droge et al. 2017) have shown that vigilance increased when predators were nearby, and that this response was stronger in locations with high LT risk (and concomitant reduction in grazing); This result aligns well with the inference that reduced speed and linearity of movement are part of a suite of responses to more cautiously assess ST risk in locations with high LT risk. More broadly, this inference aligns with the earlier suggestions that prey sometimes tolerate (or even select) predator-rich 
areas if there are advantages to doing so (for example, better opportunities to hide or escape)

532 (Wirsing et al. 2010).

Our results are somewhat in line with the results from Hopcraft et al. (2014) who studied movement parameters of wildebeests and zebra (Equus quagga). They found that most individual zebra moved more cautiously by slowing their daily movements and changing their course of direction only during the wet season, not the dry season in areas with high risks of predation. However, wildebeests generally did not respond to landscape features related to predation during the wet season, and only weakly during the dry season. They also stated that during the wet season, when the quality of grazing is at its peak, both zebras and wildebeests move the greatest distances and in large groups. They attribute the larger movement distances to bigger groups rapidly depleting localized grazing opportunities and the smaller effects of movement from predation risk to the dilution of the individuals' risk of predation by being in a large group. In LPNP the group sizes of wildebeests are much smaller, rarely reaching thousands, and thus the dilution of predation risk much less. At the same time the food quantity in LPNP is always low, with grass growing very sparsely and

546 thus diminishing the difference between good and bad grazing patches, and thus movements

547 related to this. These smaller differences in group size and forage quantity in LPNP might have given us more power to detect relationships between movement parameters and predation risk.

Prior studies have examined how ungulate movements respond to direct encounters with predators (Fischhoff et al. 2007), to 'probable encounters' inferred from GPS data on

552 both predators and prey (Creel et al. 2013; Courbin et al. 2015; Martin \& Owen-smith 2016), or to the immediate presence of predators within a distance of 2-5 kilometers (Creel et al. 2005; Proffitt et al. 2009; Latombe et al. 2014). In general, it seems clear that an increase in speed (flight) is common if prey animals are encountered at close range or hunted, but the 
effect of elevated ST risk that does not necessarily involve close, direct interaction is not well understood (e.g., compare Creel et al. 2005; Proffitt, KM et al. 2009; Latombe et al. 2014). Because flight often causes prey to speed up after close encounters, one could reasonably hypothesize that altered movement in areas of high LT risk is not a direct response to LT risk itself, but simply a by-product of more frequent ST responses to direct encounters (the 'summation of ST responses' hypothesis). Our data do not support this hypothesis. As in other studies, wildebeest often responded to being hunted, particularly by coursers, with highspeed flight over long distances, greatly exceeding the mean step length for a 4-hour period in just a few minutes. Because such responses are inevitably more frequent in areas that are heavily used by carnivores, the 'summation ST responses' hypothesis would predict an increase in mean speed in areas of high LT risk, rather than the decrease that we observed. Thus the effect of LT risk on movement patterns occurs despite reactive movements induced by ST risk.

Several studies have examined how the movements of elk and white tailed deer change during human hunting seasons lasting several days to several weeks (Root et al. 1988; Cleveland et al. 2012; Article et al. 2013; Little et al. 2016). The risk in such studies shares some attributes of ST risk in natural systems (abrupt onset, limited duration), but also shares some attributes of LT risk (elevation of risk for days or weeks, rather than minutes or hours). While it is not clear if human hunters are perceived differently than other types of human disturbance, studies have found considerable variation in responses, with increased movement in some cases (Root et al. 1988; Peckarsky et al. 1993; Cleveland et al. 2012), no detectable effect in other cases (Neumann et al. 2009). In other cases increased movement in areas exposed to hunters was detected, but not in refuges closed to hunting (Rhoads et al. 2013). The risk period in those studies was restricted to hunting season of several days to several weeks, with relatively widespread and intense risk and frequent disturbance within 
581

582

583

584

585

586

587

588

589

590

591

592

593

594

595

596

597

598

599

600

601

602

603

604

areas containing refuges and species known to hide from perceived threats. Such a study design may not allow prey to accurately assess spatial and temporal variation in risk patterns, when compared to the responses of prey to LT patterns of risk in intact ecosystems like LPNP. In human hunting studies (Root et al. 1988; Article et al. 2013; Little et al. 2016), there is also an abrupt change in the intensity of risk in an area, with risk increasing over relatively large areas for a period of intermediate length. Because these attributes are quite dissimilar to the patterns of variation in ST and LT risk typical of undisturbed predator-prey systems, it is difficult to relate inferences about effects of risk on movement from the two types of studies.

The spatial and temporal scale of exposure to risk, and the heterogeneity of risk within these spatial and temporal scales, all play roles in determining the optimal response of prey to risk (Lima \& Bednekoff 1999). Proactive adjustments of behavior in response to LT risks depend on the ability of prey to assess this risk (and to pay any costs of assessment), and on their ability to assess and respond to superimposed ST risks. Temporally, the activity peaks of predators in LPNP are predictable, although risk is appreciable throughout much of the $24 \mathrm{~h}$ day. African wild dogs concentrate hunting in the crepuscular periods, cheetahs during the day and lions and hyenas during the crepuscular periods through the night (Dröge et al. 2017). Spatially, the intensity of use of various areas by predators in our study area was stable, especially for spotted hyenas (the most abundant predator), adding to the predictability of LT variation in risk over space and time. The relative structural homogeneity of our study area causes there to be little influence of vegetation structure on risk when compared to most ecosystems, (though it also eliminates the possibility for wildebeest to retreat to natural refuges). Collectively, these properties perhaps allow better assessment and response to variation in LT risk by wildebeest in LPNP than may prove to be typical, but we need more 
605 tests of the response of movements to natural variation in risk before general patterns can be 606 identified.

607 The effect of risk on movement patterns was considerable for both speed and turning 608 angles, in comparison to the effects of bottom-up variables expected to influence wildebeest 609 movements. We found no evidence for effects due to distance to water or diet quality on 610 speed or turning angles, while there was a relationship between forage quantity and turning 611 angles and some evidence for a relationship between forage quantity and speed. Time of day 612 and time of year also had considerable effects on movements.

613 While the data suggest that movements are sensitive to risk after accounting for

614 bottom-up effects, some caveats should be noted. First, not all pans hold water year round, 615 and pans dry up at different times of the year depending on their size. Some pans persist 616 through the dry season in wet years but not in dry years. This variation is not captured by the 617 way we measured distance to water (as the distance to the nearest known pan). Consequently, 618 the weak relationship between wildebeest movements and water might be due to the

619 widespread distribution of pans across the study area, but this result might also have arisen

620 because we could not model temporal variation in pan persistence. Second, we used

621 chlorophyll measurements from fecal samples to model forage quality as a factor that varied seasonally. This allowed us to account for seasonal variation in diet quality, but did not allow

623 us to model fine scale temporal, spatial, or individual variation in diet quality. Third, forage

624 quantity was approximated from EVI values, which were linked to wildebeest locations both 625 spatially and temporally. While EVI is a good candidate to measure forage quantity, there is a 626 chance that inundation, which can occur in LPNP to varying extents between December and 627 May, influences EVI measures. Inundation might obscure the relationship between EVI and 628 green biomass. 

particular, they detected more relaxed behavior of wildebeests after moonrise, but wildebeests showed no response to the lunar position and strongly avoided areas of higher lion encounter risk. They found that all species, except gazelles, increased their level of relaxed behaviors during brighter nights and all species altered their distribution within areas with various levels and types of risk. This suggests that animals adjust their behavior and distribution on the risk they perceive. While our study was aimed to determine if prey responded measurably to probabilistic risk in the long run and we weren’t able to include lunar luminosity into our models, it is interesting to note that such patterns can also be detected at different time scales. And, like Palmer et al. (2017) note, risk varies through time and space as well. wildebeests is highest in the areas with highest predator UD. Thus, our results show that the areas with the highest predator UD have the lowest wildebeest speed and highest turning angles, these responses occur in the areas that are most heavily used by wildebeest in the long term, and it is likely that the relationships between predation risk, wildebeest density and wildebeest movements are all related. Aggregation is a common response to risk in ungulates, and the relationships of wildebeest movements and density to risk are probably not independent.

It is also possible that wildebeest movements are affected by anthropogenic variables

649 (Stabach et al. 2016) not considered here, such as the distance to the park boundary or 650 distance to settlements. Stabach et al. (2016) noted that wildebeests consistently avoided anthropogenic features and dense woody cover, which were likely associated with predation risk. We did not include these variables (even though anthropogenic features can affect wildebeest density: M’Soka et al. 2016), because we hypothesized that at the spatiotemporal 
654 scale of several hours and several hundred meters, the effects of factors that typically operate

655

656

657

658

659

660

661

662

663

664

665

666

667

668

669

670

671

672

673

674

675

676

677 at large spatiotemporal scales are likely to be weak, relative to local variation in predation risk, food and water.

Overall we detected considerable pro-active movement responses of wildebeest in LPNP to LT risk after controlling for a range of bottom-up effects, but remain cautious about the causal relationships between risk, density and movements. There is widespread evidence that behavioral changes induced by risk, whether this risk is long term or short term, are often favored by natural selection by reducing the mortal impact of that risk, for many taxa. Lima \& Bednekoff (1999) theorized that optimal antipredator responses depend on both the immediate (short term) and background (long term) level of predation risk. Because we detected behavioral responses to variation in LT risk, the logic of Lima \& Bednekoff (1999) suggests that this variation should influence their reactive responses to short term variation in risk. While our data on movement were not sufficient to test this idea, Droge et al. (2017) examined data on vigilance in this same system and found that prey (including wildebeest) reactively responded to acute ST risk more strongly in areas of high LT risk. These results have broad implications for studies that focus on ST risk without measuring or considering variation in LT risk (or vice versa). Studies examining the non-lethal effects of predators on their prey should consider both LT and ST risk, and carefully consider the spatial and temporal scales at which they examine both. As noted in the introduction these behavioral responses of prey to predation risk carry a cost to the prey. While we purely focused on movement, it is quite possible that the reduced movement is related to increased vigilance and actually costs more energy than is saved by moving less. These costs of prey can have considerable impacts on fecundity rates, survival and thus on population dynamics (Werner et al. 1983; Peckarsky et al. 1993; Boonstra et al. 1998; Pangle et al. 2007; Sheriff et al. 2009; 
678 LaManna et al. 2016) making them important to consider in the management of areas and or 679 species which are exposed to predation risk.

680 In ecosystems that hold migratory wildebeest, this species, which can dominate the ungulate 681 community by a considerable margin, has strong influences on ecosystem function and on the 682 composition, size and distribution of the large carnivore guild. Thus, conservation and management in such systems is strongly guided by consideration of factors that affect the 684 distribution, abundance and movements of wildebeest. Indeed, the boundaries of Serengeti 685 National Park were designed explicitly to encompass the migration of its famous wildebeest 686 population. The Greater Liuwa ecosystem is similarly dominated by wildebeest and they are 687 the most important prey for large carnivores in the ecosystem by an appreciable margin. Our 688 analysis contributes to the understanding of carnivore-ungulate conservation and management in the Greater Liuwa ecosystem by showing that, perhaps contrary to intuition, wildebeest do not speed up and linearize their movements in areas that are heavily used by

691 carnivores. Rather, they slow down and move in a pattern that allows more careful

692 assessment of immediate risks. This result has broad implications for understanding the 693 influence of predation risk on patterns of grazing in the Greater Liuwa ecosystem. More 694 generally, our results show that the influence of predation risk on herbivore movements is much more complex than simple avoidance of areas of 'high risk'. As with other aspects of

696 behaviour, the movements of wildebeests are affected in a complex manner by different

697 responses to long term and short term variation in risk. Interactions between carnivores and 698 their prey are complex and direct and indirect. This study provides insight into the 699 relationship between wildebeests and carnivores in Liuwa Plain National Park and 700 surroundings which contributes to the management and conservation of both in the 701 ecosystem. 
Literature Cited

Basille M et al. 2015. Plastic response of fearful prey to the spatiotemporal dynamics of predator distribution. Ecology 96:2622-2631.

Boonstra R, Hik D, Singleton GR, Tinnikov A. 1998. The impact of predator-induced stress on the snowshoe hare cycle. Ecological Monographs 68:371-394. Available from http://www.jstor.org/stable/2657244.

Broekhuis FC, Cozzi G, Valeix M, Mcnutt JW, Macdonald DW. 2013. Risk avoidance in sympatric large carnivores: reactive or predictive? Journal of Animal Ecology 82:1098_1105.

Brown GE, Chivers DP, Elvidge CK, Jackson CD, Ferrari MCO. 2014. Background level of risk determines the intensity of predator neophobia in juvenile convict cichlids. Behavioral Ecology and Sociobiology 68:127-133.

Calenge C. 2006. The package adehabitat for the R software: a tool for the analysis of space and habitat use by animals. Ecological Modelling 197:516-519.

Christianson D, Creel S. 2009. Fecal chlorophyll describes the link between primary production and consumption in a terrestrial herbivore. Ecological Applications 19:13231335.

Christianson D, Creel S. 2014. Ecosystem scale declines in elk recruitment and population growth with wolf colonization: A before-after-control-impact approach. PLoS ONE

Christianson D, Klaver RW, Middleton A, Kauffman M. 2013. Confounded winter and spring phenoclimatology on large herbivore ranges. Landscape Ecology 28:427-437.

727 Cleveland SM, Hebblewhite M, Thompson M, Henderson R, Article O. 2012. Linking elk 
movement and resource selection to hunting pressure in a heterogeneous landscape. Wildlife Society Bulletin 36:658-668. Available from http://files.cfc.umt.edu/heblab/WSB_Cleveland_IndirectEffectsofHunting_2012.pdf.

731

732

733

734

735

736

737

738

739

740

741

742

743

744

745

746

747

Courbin N, Loveridge AJ, Macdonald DW, Fritz H, Valeix M, Makuwe ET, Chamailléjammes S. 2015. Reactive responses of zebras to lion encounters shape their predatorprey space game at large scale. Oikos 125:829-838.

Creel S et al. 2005. Elk Alter Habitat Selection As an Antipredator Response To Wolves. Ecology 86:3387-3397. Available from http://doi.wiley.com/10.1890/05-0032.

Creel S, Christianson D, Liley S, Winnie JA. 2007. Predation Risk Affects Reproductive Physiology and Demography of Elk. Science 315:960-960. Available from http://www.sciencemag.org/content/315/5814/960\%5Cnhttp://www.ncbi.nlm.nih.gov/pu bmed/17303746\%5Cnhttp://www.sciencemag.org/content/315/5814/960.full.pdf\%5Cnht tp://www.sciencemag.org/content/315/5814/960.short.

Creel S, Dröge ED, M’soka JLJ, Smit D, Becker MS, Christianson DA, Schuette PA. 2017. The relationship between direct predation and antipredator responses : a test with multiple predators and multiple prey. Ecology 98:2081-2092.

Creel S, Schuette P, Christianson D. 2014. Effects of predation risk on group size, vigilance, and foraging behavior in an African ungulate community. Behavioral Ecology 25:773784.

Creel S, Winnie JA. 2005. Responses of elk herd size to fine-scale spatial and temporal variation in the risk of predation by wolves. Animal Behaviour 69:1181-1189.

Creel S, Winnie JA, Christianson D. 2013. Underestimating the frequency, strength and cost of antipredator responses with data from GPS collars: An example with wolves and elk. Ecology and Evolution 3:5189-5200.

Creel S, Winnie JA, Christianson D, Liley S. 2008. Time and space in general models of 
antipredator response: tests with wolves and elk. Animal Behaviour 76:1139-1146.

754

755

756

757

758

759

760

761

762

763

764

765

766

767

768

769

770

771

772

773

774

775

776

777

Cribari-Neto F, Zeileis A. 2010. Beta Regression in R. Journal of Statistical Software 34:124. Available from http://www.jstatsoft.org/v34/i02/.

Droge E, Creel S, Becker MS. 2017. Risky times and risky places interact to affect prey behaviour. Nature Ecology \& Evolution 1: 1123-1128.

Dröge ED, Creel S, Becker MS, M’Soka JLJ. 2017. Spatial and temporal avoidance of risk within a large carnivore guild. Ecology and Evolution 7:189-199.

Elgar MA. 1989. Predator vigilance and group size in mammals and birds: a critical review of the empirical evidence. Biology Reviews 64:13-33.

Ferrari SLP, Cribari-Neto F. 2004. Beta regression for modelling rates and proportions. Journal of Applied Statistics 31:799-815.

Fischhoff IR, Sundaresan SR, Cordingley J, Rubenstein DI. 2007. Habitat use and movements of plains zebra (Equus burchelli) in response to predation danger from lions. Behavioral Ecology 18:725-729.

Fitzgibbon CD. 1989. A cost to individuals with reduced vigilance in groups of Thomson's gazelles hunted by cheetahs. Animal Behaviour 37:508-510.

Fitzgibbon CD. 1990. Mixed-species grouping in Thomson’s and Grant’s gazelles: the antipredator benefits. Animal Behaviour 39:1116-1126.

Forchhammer MC, Post E. 2004. Using large-scale climate indices in climate change ecology studies. Population Ecology 46:1-12.

Fortin D, Beyer HL, Boyce MS, Smith DW, Duchesne T, Mao JS. 2005. Wolves Influence Elk Movements: Behavior Shapes a Trophic Cascade in Yellowstone National Park. Ecology 86:1320-1330.

Frair JL, Merrill EH, Visscher DR, Fortin D, Beyer HL, Morales JM. 2005. Scales of movement by elk (Cervus elaphus) in response to heterogeneity in forage resources and 
predation risk. Landscape Ecology 20:273-287.

779

780

781

782

783

784

785

786

787

788

789

790

791

792

793

794

795

796

797

798

799

800

801

802

Gerritsen J, Strickler JR. 1977. Encounter probabilities and community structure in zooplankton: a mathematical model. Journal of the Fisheries Research Board Canada 34:73-82.

Hebblewhite M, Pletscher DH, Paquet PC. 2002. Elk population dynamics in areas with and without predation by recolonizing wolves in Banff National Park, Alberta. Canadian Journal of Zoology 80:789-799. Available from

http://www.nrcresearchpress.com/doi/abs/10.1139/z02-058.

Hopcraft JGC, Morales JM, Beyer HL, Borner M, Mwangomo E, Sinclair ARE, Olff H, Haydon DT. 2014. Competition, predation, and migration: Individual choice patterns of Serengeti migrants captured by hierarchical models. Ecological Monographs 84:355372.

Kauffman MJ, Varley N, Smith DW, Stahler DR, MacNulty DR, Boyce MS. 2007. Landscape heterogeneity shapes predation in a newly restored predator-prey system. Ecology Letters 10:690-700.

Kuijper DPJ et al. 2013. Landscape of fear in Europe: Wolves affect spatial patterns of ungulate browsing in Bialowieza Primeval Forest, Poland. Ecography 36:1263-1275.

LaManna JA, Martin TE, Letters E, LaManna JA, Martin TE, Letters E, LaManna JA, Martin TE, Letters E. 2016. Costs of fear: Behavioural and life-history responses to risk and their demographic consequences vary across species. Ecology Letters 19:403-413.

Latombe G, Fortin D, Parrott L. 2014. Spatio-temporal dynamics in the response of woodland caribou and moose to the passage of grey wolf. Journal of Animal Ecology 83:185-198. Laundré JW, Hernández L, Altendorf KB. 2001. Wolves, elk, and bison: reestablishing the “landscape of fear” in Yellowstone National Park, U.S.A. Canadian Journal of Zoology 79:1401-1409. 
803 Lima SL, Bednekoff P a. 1999. Temporal Variation in Danger Drives Antipredator Behavior :

804 The Predation Risk Allocation Hypothesis. The American Naturalist 153:649-659.

805 Little AR, Webb SL, Demarais S, Gee KL, Riffell SK, Gaskamp JA. 2016. Hunting intensity

806 alters movement behaviour of white-tailed deer. Basic and Applied Ecology 17:360-

807 369. Elsevier GmbH.

808 M'Soka JLJ, Creel S, Becker MS, Murdoch JD, Creel S, Becker MS, Murdoch JD. 2017.

809 Ecological and anthropogenic effects on the density of migratory and resident ungulates

810 in a human-inhabited protected area. African Journal of Ecology 55:1-14.Martin J,

811 Owen-smith N. 2016. Habitat selectivity influences the reactive responses of African

812 ungulates to encounters with lions. Animal Behaviour 116:163-170. Elsevier Ltd.

813 McCarthy TM, Fisher WA. 2000. Multiple predator-avoidance behaviours of the freshwater

814 snail Physella heterostropha pomila:responses vary with risk. Freshwater Biology

$815 \quad 44: 387-397$.

816 McNaughton S. 1979. Grazing as an Optimization Process : Grass-Ungulate Relationships in

817 the Serengeti Author ( s ): S . J . McNaughton Source : The American Naturalist, Vol .

818113 , No . 5 ( May , 1979 ), pp . 691-703 Published by: The University of Chicago Press

819 for The A. The American Naturalist 113:691-703.

820

Moll RJ, Killion AK, Montgomery RA, Tambling CJ, Hayward MW, M RAJ, K AK, M RAJ,

821 T CJ. 2016. Spatial patterns of African ungulate aggregation reveal complex but limited

822 risk effects from reintroduced carnivores. Ecology 97:1123-1134. Available from

823 http://www.esajournals.org/doi/10.1890/15-0707.1.

824 Murray MG, Illius AW. 2000. Vegetation modification and resource competition in grazing $825 \quad$ ungulates. Oikos 89:501-508.

826 Neumann W, Ericsson G, Dettki H. 2009. The non-impact of hunting on moose Alces alces

827 movement, diurnal activity, and activity range. European Journal of Wildlife Research 
Newcombe RG. 1998. Two-Sided Confidence Intervals for the Single Proportion:

Palmer MS, Fieberg J, Swanson A, Kosmala M, Packer C. 2017. A ‘dynamic’ landscape of fear: prey responses to spatiotemporal variations in predation risk across the lunar cycle. Ecology Letters 20:1364-1373.

Pangle KL, Peacor SD, Johansson OE, Johannsson OE. 2007. Large nonlethal effects of an invasive invertebrate predator on zooplankton population growth rate. Ecology 88:402412.

Peckarsky BL, Cowan CA, Penton MA, Cowan CA, Penton MA, Anderson C. 1993. Sublethal consequences of stream-dwelling predatory stoneflies on mayfly growth and fecundity. Ecology 74:1836-1846. Available from http://www.jstor.org/stable/1939941.

Périquet S et al. 2012. Influence of immediate predation risk by lions on the vigilance of prey of different body size. Behavioral Ecology.

Pettorelli N, Vik JO, Mysterud A, Gaillard J-M, Tucker CJ, Stenseth NC. 2005. Using the satellite-derived NDVI to assess ecological responses to environmental change. Trends in Ecology \& Evolution 20:503-510.

Proffitt KKM et al. 2009. Contrasting Effects of Wolves and Human Hunters on Elk Behavioral Responses to Predation Risk. Journal of Wildlife Management 73:345-356. Available from http://www.jstor.org/stable/40208534.

R Core Team. 2016. R: A language and environment for statistical computing. R Foundation for Statistical Computing, Vienna, Austria. Available from http://www.r-project.org/. response to controlled hunts. Wildlife Society Bulletin 37:631-638.

852 Root BG, Fritzell EK, Giessman NF. 1988. Effects of intensive hunting on white-tailed deer 
853

854

855

856

857

858

859

860

861

862

863

864

865

866

867

868

869

870

871

872

873

874

875

876

877

movement. Wildlife Society Bulletin 16:145-151. Available from http://www.jstor.org/stable/3782181.

Schmitz OJ. 2008. Effects of predator hunting mode on grassland ecosystem function. Science (New York, N.Y.) 319:952-4. Available from http://www.ncbi.nlm.nih.gov/pubmed/18276890.

Schmitz OJ. 2012. Direct and indirect effects of predation and predation risk in old-field interaction webs. The American Naturalist 151:327-342.

Seaman ED, Powell RA, Seaman DE, Powell RA. 1996. An evaluation of the accuracy of kernel density estimators for home range analysis. Ecology 77:2075-2085. Available from http://www.jstor.org/stable/2265701.

Sheriff MJ, Krebs CJ, Boonstra R. 2009. The sensitive hare: Sublethal effects of predator stress on reproduction in snowshoe hares. Journal of Animal Ecology 78:1249-1258.

Shrader AM, Owen-Smith N, Ogutu JO. 2006. How a mega-grazer copes with the dry season: food and nutrient intake rates by white rhinoceros in the wild. Functional Ecology 20:376-384.

Sih A, McCarthy TM. 2002. Prey responses to pulses of risk and safety: testing the risk allocation hypothesis. Animal Behaviour 63:437-443.

Skelly DK, Werner EE, Skelly DK, Werner EE. 2016. Behavioral and life-historical responses of larval American toads to an odonate predator. Ecology 71:2313-2322. Available from http://www.jstor.org/stable/1938642.

Stabach JA, Wittemyer G, Boone RB, Reid RS, Worden JS. 2016. Variation in habitat selection by white-bearded wildebeest across different degrees of human disturbance. Ecosphere 7:1-17.

Thaker M et al. 2011. Minimizing predation risk in a landscape of multiple predators: effects on the spatial distribution of African ungulates. Ecology 92:398-407. 
878

879

880

881

882

883

884

885

886

887

888

889

890

891

892

893

894

895

896

897

898

899

900

901

902

Valeix M, Loveridge AJ, Chamaillé-Jammes S, Davidson Z, Murindagomo F, Fritz H, Macdonald DW. 2009. Behavioral adjustments of African herbivores to predation risk by lions: spatiotemporal variations influence habitat use. Ecology 90:23-30. Available from http://www.ncbi.nlm.nih.gov/pubmed/19294909.

Venables WN, Ripley BD. 2002. Modern Applied Statistics with S. Springer, New York.

Viswanathan GM, Buldyrev S V, Havlin S, da Luz MGE, Raposo EP, Stanley HE. 1999. Optimizing the success of random searches. Nature 401:911-914.

Werner EE, Gilliam JF, Hall DJ, Mittelbach GG. 1983. An experimental test of the effects of predation risk on habitat use in fish. Ecology 64:1540-1548. Available from http://www.jstor.org/stable/1937508.

Wilmshurst JF, Fryxell JM, Hudson RJ. 1995. Forage quality and patch choice by wapiti (Cervus elaphus). Behavioral Ecology 6:209-217.

Winnie J, Creel S, Winnie Jr JA, Creel S, Winnie J, Creel S, Winnie Jr JA, Creel S. 2007. Sex-specific behavioural responses of elk to spatial and temporal variation in the threat of wolf predation. Animal Behaviour 73:215-225.

Wirsing AJ, Cameron KE, Heithaus MR. 2010. Spatial responses to predators vary with prey escape mode. Animal Behaviour 79:531-537. Elsevier Ltd. Available from http://dx.doi.org/10.1016/j.anbehav.2009.12.014.

Worton BJ, Worton ABJ. 1989. Kernel Methods for Estimating the Utilization Distribution in Home-Range Studies. Ecology 70:164-168. Available from http://www.jstor.org/stable/1938423.

(1)

(1)

(1) 


\begin{tabular}{|r|c|c|c|c|}
\hline Parameter & $\begin{array}{c}\text { Effect on } \\
\text { Speed }\end{array}$ & SE & $\begin{array}{c}\text { Test } \\
\text { Statistic }\end{array}$ & $\boldsymbol{P}$ \\
\hline Intercept & -1.211 & 0.044 & -27.58 & $<0.0001$ \\
\hline LT risk (all predators) & -0.161 & 0.008 & -19.65 & $<0.0001$ \\
\hline Autocorrelation & 0.132 & 0.007 & 18.52 & $<0.0001$ \\
\hline Daily Activity: Low & -0.483 & 0.017 & -28.84 & $<0.0001$ \\
\hline Distance to Water & 0.017 & 0.007 & 2.33 & 0.02 \\
\hline Diet Quality: Low & -0.010 & 0.043 & -0.23 & 0.82 \\
\hline Forage Quantity (EVI) & -0.014 & 0.008 & -1.72 & 0.09 \\
\hline POST parturition & 0.007 & 0.030 & 0.25 & 0.80 \\
\hline PRE parturition & -0.020 & 0.058 & -0.34 & 0.73 \\
\hline Day of Year (sin) & 0.077 & 0.010 & -7.80 & $<0.0001$ \\
\hline Day of Year (cosine) & -0.025 & 0.008 & -3.28 & 0.002 \\
\hline
\end{tabular}

903

904

905

906

907

908

909

910

911

912

913

914

915

916

917

918

919

920

921

922

923

924

Table 1: Scaled effects on speed of movement by wildebeest. Here, LT risk was described by the utilization distribution for all predators. ${ }^{1}$ : reference level is high activity periods. ${ }^{2}$ : reference level is high diet quality periods. ${ }^{3}$ : reference level is 'not affected' by late gestation or a newborn calf. Model $\mathrm{R}^{2}=0.20$.

\begin{tabular}{|c|c|c|c|}
\hline $\begin{array}{c}\text { Description of } \\
\text { Risk }\end{array}$ & $\boldsymbol{d} \boldsymbol{f}$ & AIC & $\boldsymbol{\Delta A I C}$ \\
\hline All predators & 9 & $21,062.75$ & 0 \\
\hline Hyena & 9 & $21,066.18$ & 3.43 \\
\hline Coursers & 9 & $21,069.47$ & 6.72 \\
\hline Lion & 9 & $21,081.21$ & 18.46 \\
\hline Stalkers & 9 & $21,140.42$ & 77.67 \\
\hline Wild Dog & 9 & $21,189.46$ & 126.71 \\
\hline Cheetah & 9 & $21,201.53$ & 138.78 \\
\hline No Risk & 8 & $21,439.94$ & 377.19 \\
\hline
\end{tabular}

Table 2: A comparison of alternative measures of LT risk in the full model of effects on wildebeest movements, using AIC scores.

(1)




\begin{tabular}{|c|c|c|c|c|}
\hline Parameter & $\begin{array}{c}\text { Effect on } \\
\text { angle }\end{array}$ & SE & $\begin{array}{c}\text { Test } \\
\text { statistic }\end{array}$ & $\boldsymbol{P}$ \\
\hline (Intercept) & -0.707 & 0.068 & -10.44 & $<0.0001$ \\
\hline LT risk (all predators) & 0.042 & 0.012 & 3.33 & 0.0008 \\
\hline Autocorrelation & -0.122 & 0.011 & -11.48 & $<0.0001$ \\
\hline Daily activity Low ${ }^{1}$ & -0.570 & 0.026 & -22.20 & $<0.0001$ \\
\hline Distance to water & -0.004 & 0.011 & -0.36 & 0.72 \\
\hline Diet Quality: Low ${ }^{2}$ & -0.014 & 0.067 & -0.21 & 0.83 \\
\hline Forage Quantity (EVI) & -0.030 & 0.013 & -2.29 & 0.02 \\
\hline POST parturition ${ }^{3}$ & 0.036 & 0.047 & -0.77 & 0.44 \\
\hline PRE parturition ${ }^{3}$ & 0.007 & 0.090 & 0.08 & 0.94 \\
\hline Day of Year (sin) & 0.0526 & 0.01507 & 3.49 & 0.0005 \\
\hline Day of Year $(\cos )$ & 0.0141 & 0.01268 & 1.11 & 0.27 \\
\hline
\end{tabular}

Table 3: Scaled effects on displacement angles for wildebeest movements. ${ }^{1}$ : reference level is high activity periods. ${ }^{2}$ : reference level is high diet quality periods. ${ }^{3}$ : reference level is 'not affected' by late gestation or a newborn calf. $\mathrm{R}^{2}=0.09$.

\begin{tabular}{|r|c|c|c|c|}
\hline $\begin{array}{r}\text { Species } \\
\text { Compared }\end{array}$ & $\begin{array}{c}\text { Log Difference } \\
\text { in Distance }\end{array}$ & $\begin{array}{c}\text { Lower } \\
\text { CI }\end{array}$ & $\begin{array}{c}\text { Upper } \\
\text { CI }\end{array}$ & $\boldsymbol{P}$ \\
\hline Hyena-Cheetah & 0.68 & -0.47 & 1.83 & 0.407 \\
\hline Lion-Cheetah & -0.64 & -2.30 & 1.01 & 0.738 \\
\hline Wild Dog-Cheetah & 1.59 & 0.31 & 2.88 & 0.009 \\
\hline Lion-Hyena & -1.33 & -2.72 & 0.06 & 0.067 \\
\hline Wild Dog-Hyena & 0.91 & -0.01 & 1.83 & 0.053 \\
\hline Wild Dog-Lion & 2.24 & 0.73 & 3.74 & 0.001 \\
\hline
\end{tabular}

Table 4: Pair-wise differences in the distances (on a log scale) that wildebeest ran in direct encounters with each predator in LPNP, Zambia, with 95\% confidence intervals. Positive 


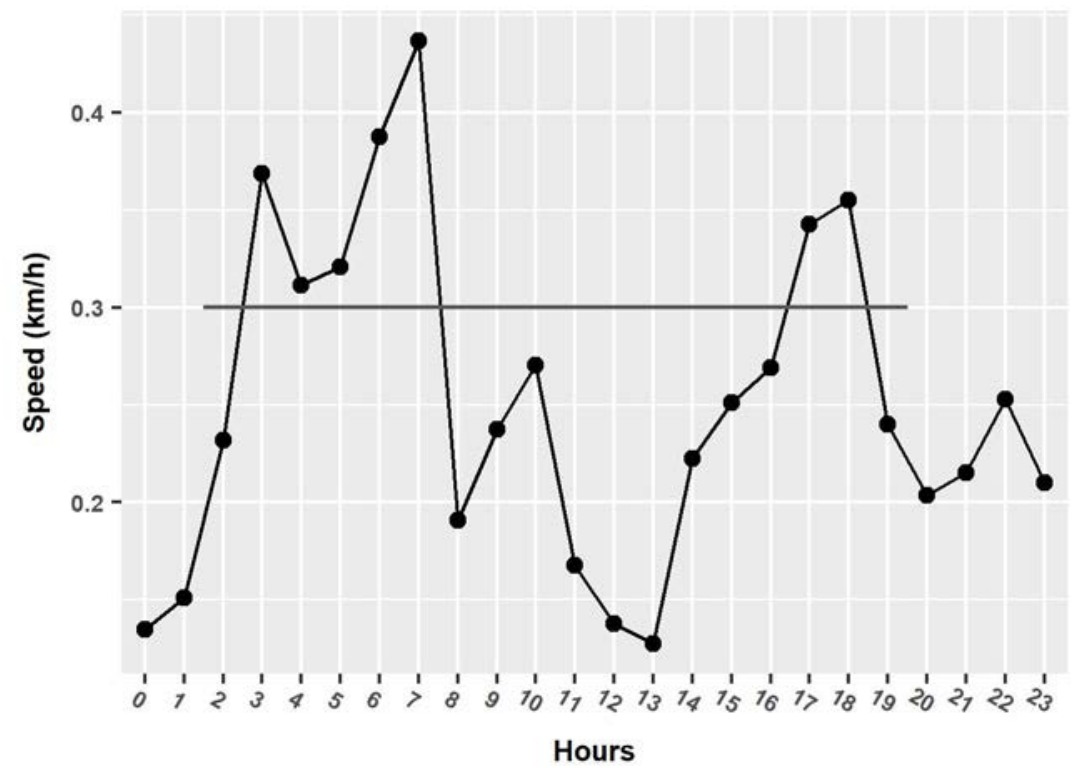

940 Figure 1: Average speed $(\mathrm{km} / \mathrm{h})$ of movement for periods centered on each hour of the day. 941 The horizontal bar denotes threshold of $0.3 \mathrm{~km} / \mathrm{h}$ defining time periods as High or Low 942 Activity.

943

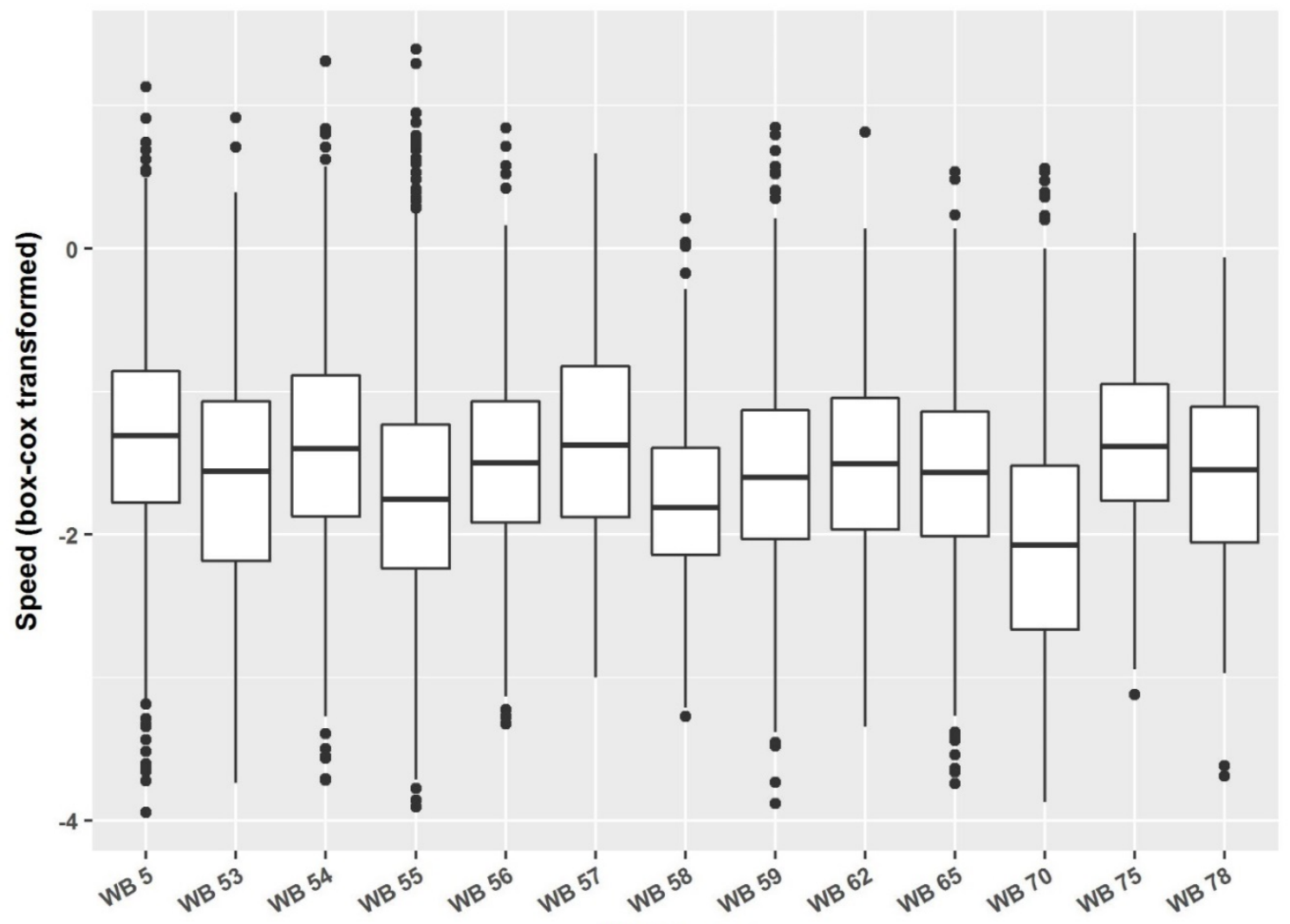

945 Figure 2: Variation within and between individual wildebeest in box-cox transformed speed 946 of movement over 4 hour time steps (median, interquartile range, range, outliers). 


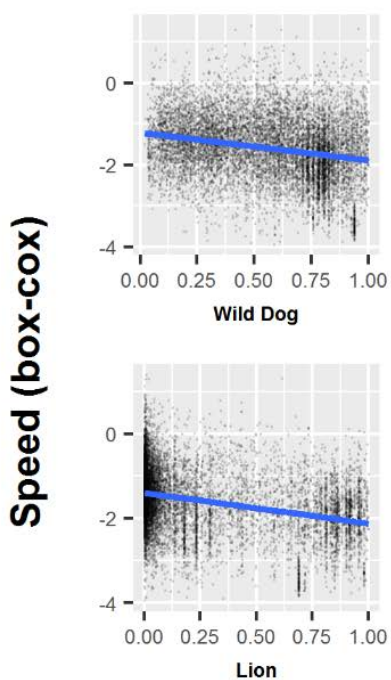

Lion

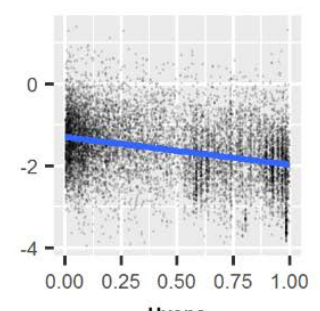

Hyena

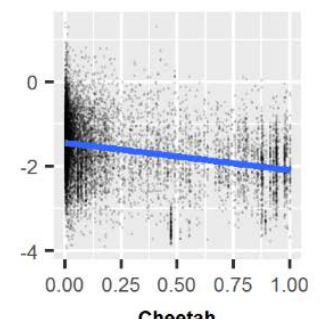

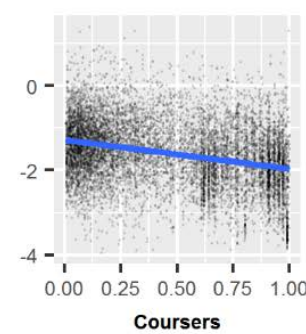

Coursers

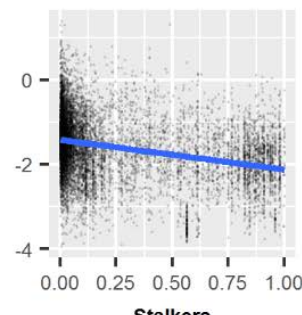

Stalkers

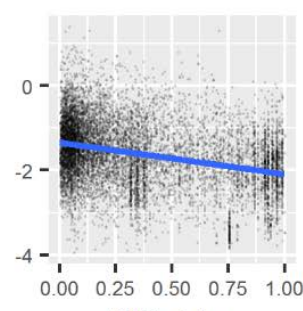

All Predators

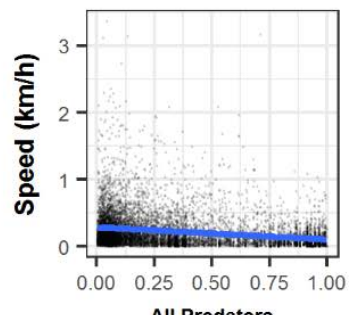

All Predators

949 Figure 3: The effect of predation risk on speed of wildebeest movements for linear models 950 containing different descriptions of LT risk (by predator species, predator type and for all 951 predators combined). The lower right panel shows the backtransformed response of speed 952 $(\mathrm{km} / \mathrm{h})$ to the LT risk from all predators, which was the best-supported model of risk (top right panel, and see Table 2 ). 


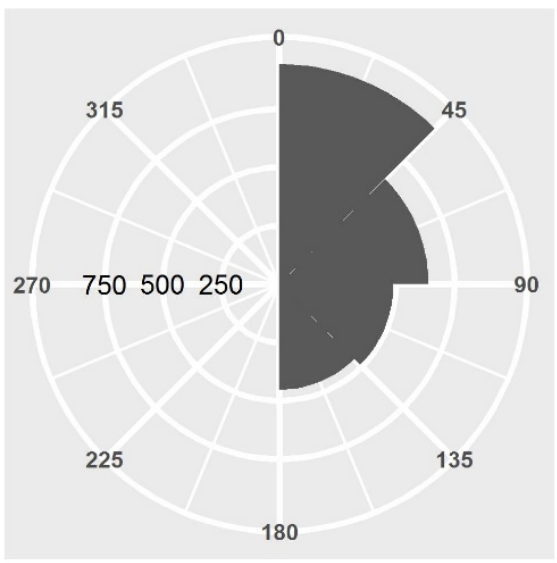

Lowest Risk

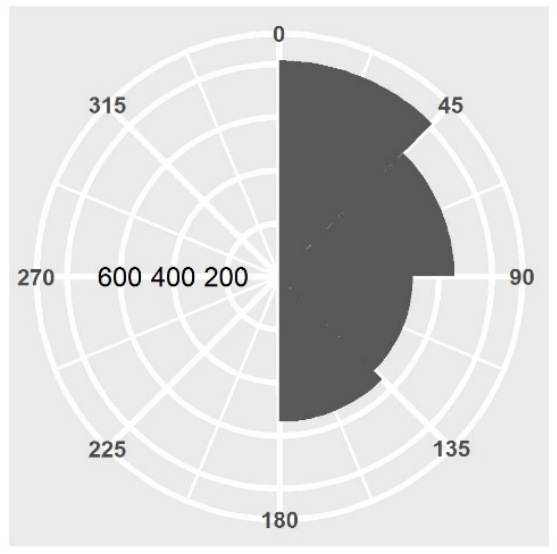

Higher Risk

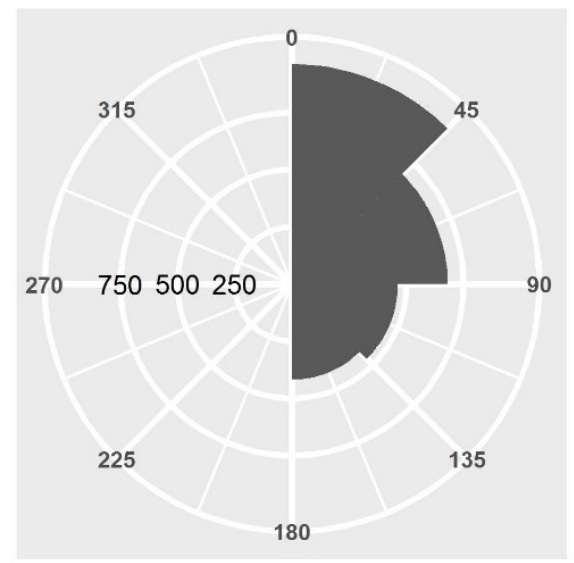

Moderate Risk

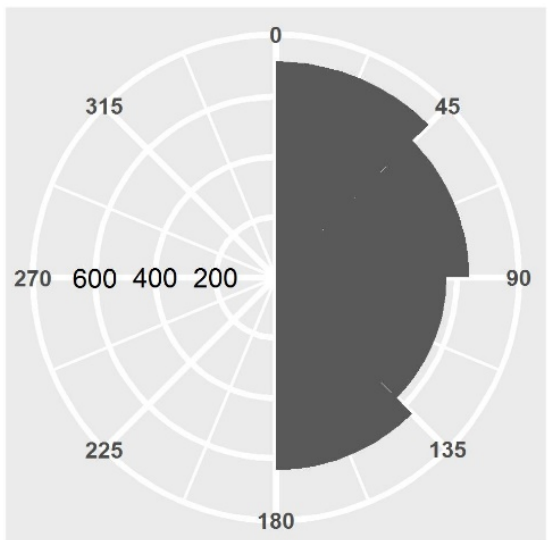

Highest Risk

955 Figure 4: The frequency distributions of deflection angles for four categories of LT risk show 956 that large deflections were more common under conditions of high risk. The four categories 957 were defined by the quartiles of the LT risk distribution (as measured by the UD of all 958 predators) and bearing categories reflect categories of turning angles. 
Simulated Path at Lowest Risk

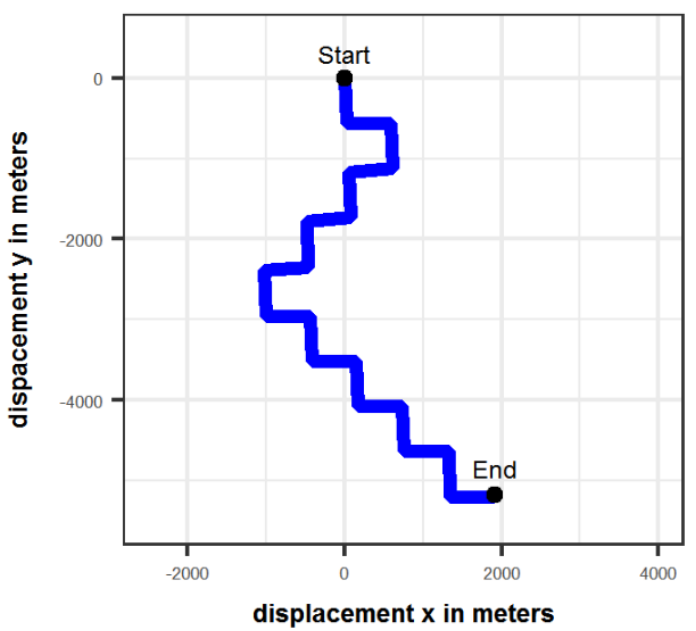

Simulated Path at Highest Risk

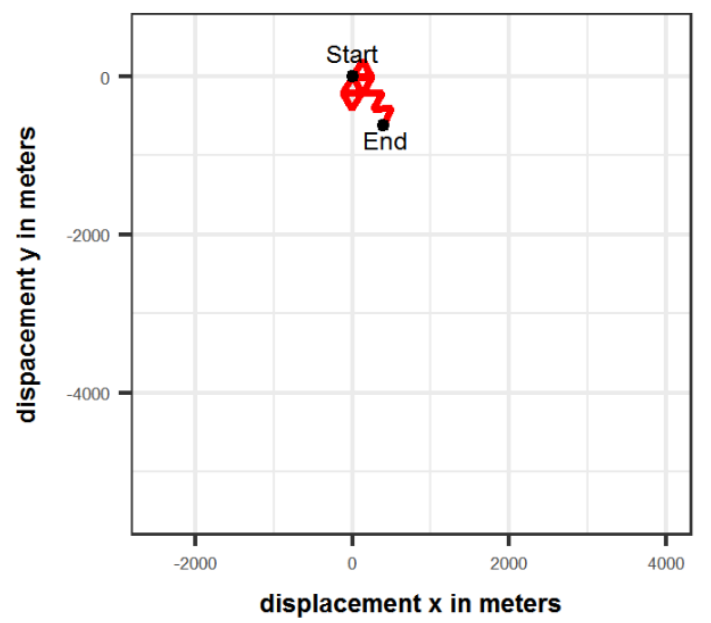

961

Figure 5: Simulation paths for 20 steps of 4 hours with predicted step lengths and deflection

962 angles for areas with the lowest and highest LT risk. Grid cells are $1 \mathrm{~km} 2$.

964

965

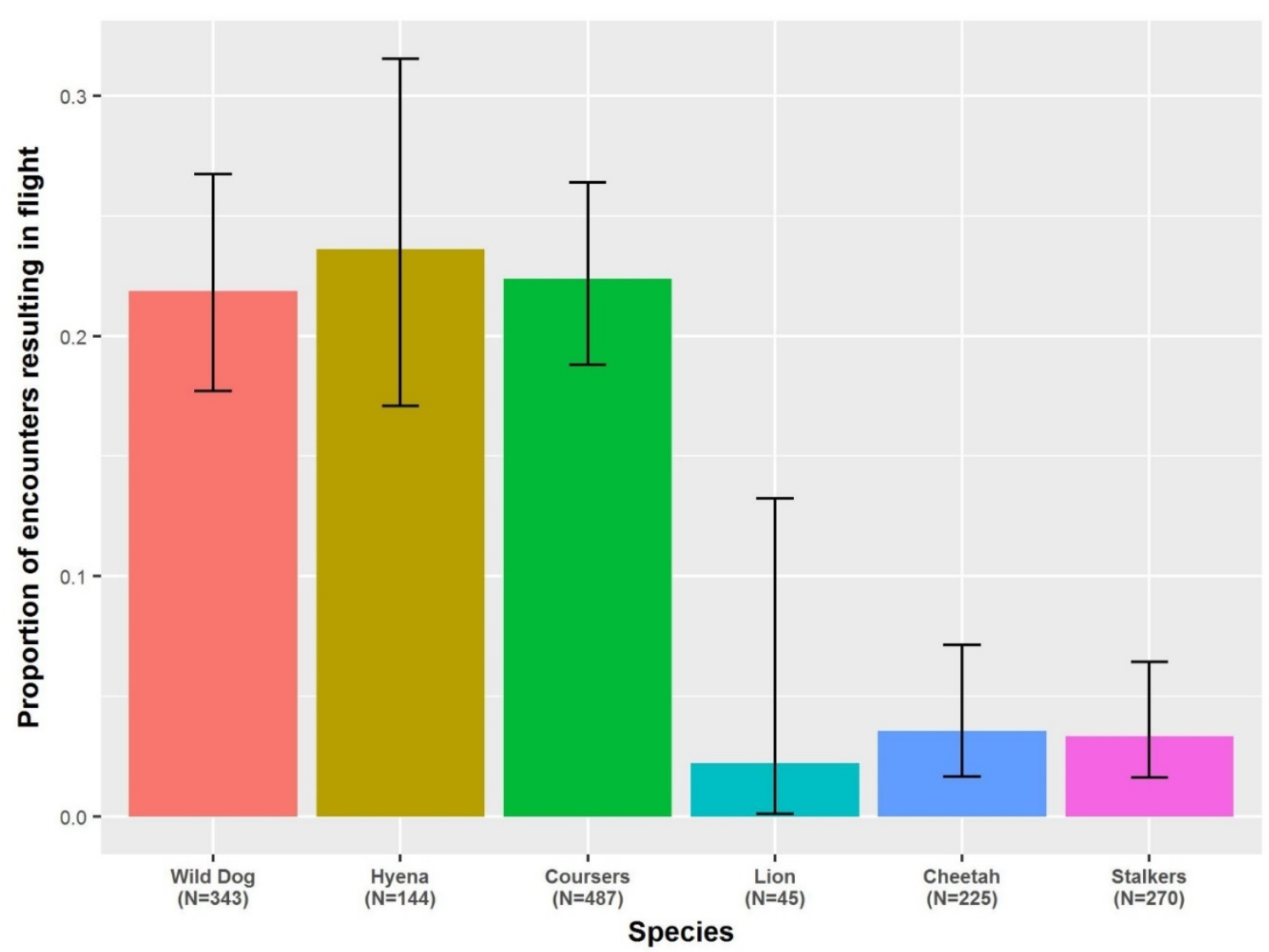

Figure 6: The proportion of encounters between predators and wildebeests that resulted in 968 flight by the wildebeest. The whiskers represent the 95\% binomial confidence interval. 


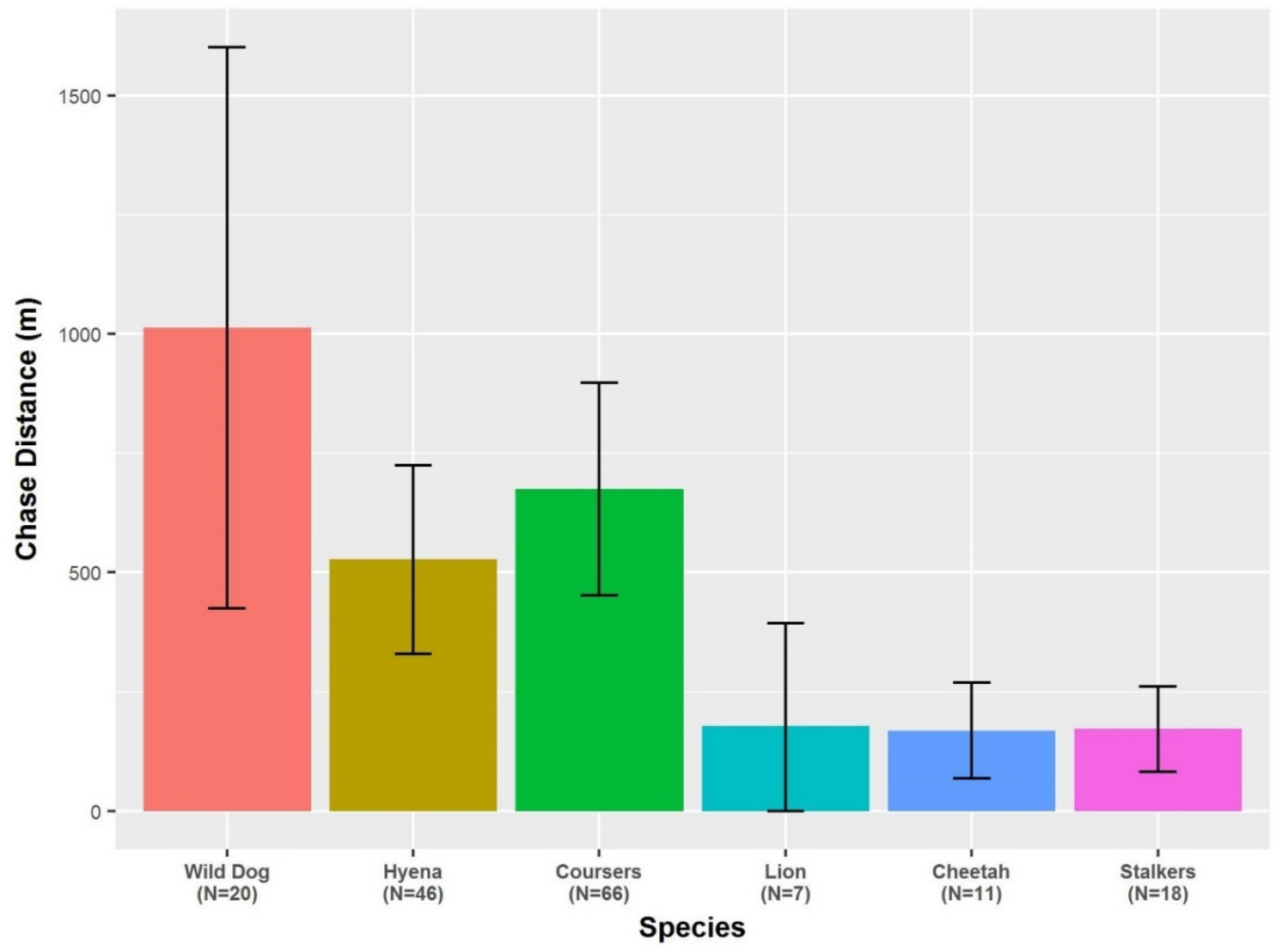

971 Figure 7: Average chase distances of wildebeests by the various predators and their 95\% 972 binomial confidence intervals. 


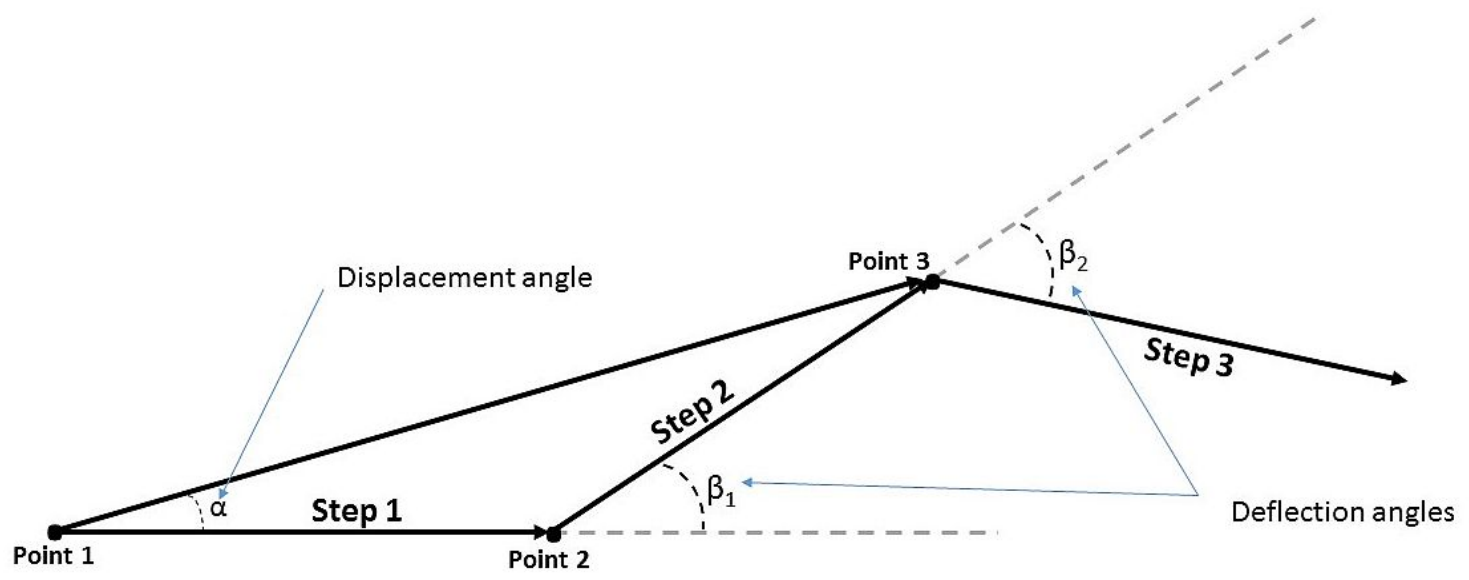

Appendix I: Schematic view of step length (speed), displacement angle $(\alpha)$ and deflection angle $(\beta)$ for wildebeest movement paths. Speed during Step 1 is associated with Point 1. Because they are affected by the change in bearing at Point 2, displacement angle $\alpha$ and deflection angle $\beta_{1}$ are both associated with Point 2 .

Appendix II

\begin{tabular}{|c|c|c|c|c|}
\hline Parameter & $\begin{array}{c}\text { Effect on } \\
\text { Speed } \\
\end{array}$ & SE & $\begin{array}{c}\text { Test } \\
\text { Statistic }\end{array}$ & $\boldsymbol{P}$ \\
\hline Intercept & -1.223 & 0.066 & -18.6 & $<0.0001$ \\
\hline LT risk (all predators) & -0.170 & 0.011 & -14.59 & $<0.0001$ \\
\hline Autocorrelation & 0.157 & 0.01 & 14.95 & $<0.0001$ \\
\hline Daily Activity: Low ${ }^{1}$ & -0.582 & 0.025 & -23.04 & $<0.0001$ \\
\hline Distance to Water & -0.003 & 0.01 & -0.32 & 0.75 \\
\hline Diet Quality: Low ${ }^{2}$ & -0.0001 & 0.064 & -0.002 & 0.998 \\
\hline Forage Quantity (EVI) & -0.0279 & 0.012 & -2.29 & 0.024 \\
\hline POST parturition $^{3}$ & -0.129 & 0.077 & -1.67 & 0.095 \\
\hline PRE parturition ${ }^{3}$ & -0.069 & 0.231 & -0.3 & 0.76 \\
\hline Day of Year (sin) & -0.056 & 0.014 & -4.12 & $<0.0001$ \\
\hline Day of Year (cosine) & -0.0025 & 0.011 & -0.22 & 0.825 \\
\hline
\end{tabular}

Appendix II: Scaled effects on speed of movement by wildebeest on the dataset restricted to locations with an EVI value from within 10 days and LT risk described by the utilization distribution for all predators. The only difference is that on this restricted dataset there is no evidence that distance to water is related to differences in speed. ${ }^{1}$ : reference level is high activity periods. ${ }^{2}$ : reference level is high diet quality periods. ${ }^{3}$ : reference level is 'not affected' by late gestation or a newborn calf. Model $\mathrm{R}^{2}=0.20$. 